Available online on 15.12.2020 at http://jddtonline.info
Open Access to Pharmaceutical and Medical Research

Open Access

Review Article

\title{
Assessing the Role of Modern Excipients for Delivery of Gold Nanoparticles
}

\author{
Abdul Waheed ${ }^{*}$, Nayela Ghazal ${ }^{2}$ \\ ${ }^{1}$ Centre of Biochemistry, Drug Design and Cancer Research, University of Salford, England \\ 2 Department of Quality Assurance, Assistant Professor, Global College of Pharmacy, (JNTU-Hyderabad), India
}

\begin{abstract}
Using the drug delivery approach, we explain the role lipids and polymers perform in the delivery of gold nanoparticles. They were tested alongside drug and polymer compatibility using pharmacodynamics and pharmacokinetics. The collected data demonstrate the production of gold nanoparticles' stability and strong therapeutic effects. We illustrate some of the intriguing categories of targeting systems for the delivery of Au G Nanoparticles that are under development. Polymers containing reactive functional groups to combine targeting binding sites, cell receptors, or drugs are also coated with nanoparticles engineered for biomedical applications. The present review focuses on utilization of modern excipients, lipids, polymers in formulation of delivery systems that can efficiently delivery the gold nanoparticles. Gold nanoparticles have outranged in their use for treating wide health diseases with limited side effects. The next generation medical deliverables are majorly focused on gold nanoparticles.
\end{abstract}

Keywords: Gold nanoparticles, Lipids, Polymers, Delivery systems, Excipients, Diseases.

Article Info: Received 12 Oct 2020; $\quad$ Review Completed 17 Nov 2020; $\quad$ Accepted 21 Nov 2020; $\quad$ Available online 15 Dec 2020

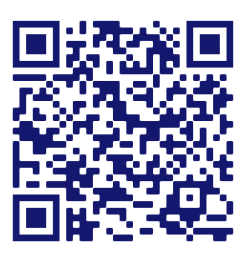

Cite this article as:

Waheed A, Ghazal N, Assessing the Role of Modern Excipients for Delivery of Gold Nanoparticles, Journal of Drug Delivery and Therapeutics. 2020; 10(6-s):151-158 http://dx.doi.org/10.22270/jddt.v10i6-s.4585

*Address for Correspondence:

Abdul Waheed, Centre of Biochemistry, Drug Design and Cancer Research, University of Salford, England

\section{Introduction:}

Gold Nanoparticles are an important component of nanotechnology and nanomedicine that has an increased therapeutic application. The gold Nanoparticles are widely used in nanomedicine based on their size \& shape. By fluctuating the material characteristics of the gold Nanoparticles, a different number of therapeutic uses of nanoparticles are enabled i.e. novel drug delivery, targeting, labeling, therapeutic uses, and diagnosis tools. Methotrexate (MTX) is a chemotherapy drug modernly used in the treatment of different types of cancers. MTX based gold nanoparticles are extensively in the field of oncology. Moreover, gold nanoparticles in the development of a wide range of innovative drug delivery systems due to their big surface: volume ratio. The transfer of drug active pharmaceutical ingredient agents to the cells by gold nanomaterials is a censorious procedure in pharmacological and medical treatment. Many professionals have used gold Nanoparticles to investigate cell organelle interaction to enhance the therapeutic effect of drug delivery. The demonstration of the surface pattern of ligands on gold Nanoparticles can control cell membrane perforation. A study showed that chitosan nanoparticle packed with 
methotrexate has suggested factorial design methodology is useful for drug delivery 1. Nanomaterials have many revolutionary applications in medicine due to their unique and novel physiochemical properties. For example, due to their relatively small size, combined with the fact that biological processes exist in nanoscale, nanomaterials can easily penetrate cells and interact with biological systems in ways that bulk materials cannot 2,3 There are numerous techniques such as lipid and polymer -based processes for the formulation of solid dispersion, complexing, crystallization, micronization, and nanonization, among which the solid dispersion technique is one of the commonly used methods to increase the solubility of poorly watersoluble drugs for clinical use. ${ }^{4}$.

\section{Types of Gold Nanoparticles:}

Gold nanoparticles can be produced as being more standard particles and with properly controlled size design shape. And morphology through a broad range of solution-phase approaches. Prominent cases involve nanotubes, nanocages, nano frames, nano boxes, nano Spears, nanoplates in such an opportunity to learn about different categories of biomedical applications such as tuning the photoluminescence (Figure1). The structures of nanocrystals may vary. Polymerbased nanocrystals can be used as a quality control tool in nanoformulation and their using the RP-HPLC method 5-7. Another research says that polymer-based nanocrystals for estimating piroxicam using the RP-HPLC method can be used as a nanoformulation quality control tool 8-12. Although gold nanoparticles are wine red solution and are claimed to be antioxidant, they are heavy and inert. In deciding the properties of these nanoparticles, inter-particle interactions and the alignment of networks of gold nanoparticles play a key role. Gold nanoparticles have diverse sizes ranging from $1 \mathrm{~nm}$ to $8 \mu \mathrm{m}$ and various shapes such as circular, suboctahedral, octahedral, decahedral, multiple twined icosahedral, multiple twined, irregular form, tetrahedral, nano triangles, nanoprisms, hexagonal platelets, and nanorods are also available as sown in the image-1 13-18.

Zein has potential uses in many applications of nanoparticles by forming proteins such as digestion of functional ingredients or active biodegradable packaging and enhancing stability. Research showed that zine-coated MgO nanowires are bioactive and can be effective antibacterial agents in dental products ${ }^{\mathbf{1 9 - 2 4}}$. Another research study found that zein with $\mathrm{ZnO}$-coated nanoparticles has antimicrobial content that can be used as a dental aid to reinvent an antibacterial delivery method. Okra gum is a plant-based extract commonly used as a bioreducer, since nanoparticles can be resized, arranged, and formed and also used in the synthesis of gold nanoparticles, which is an excellent reducing agent. Research has shown that plant-based polymeric okra gum can be used successfully in the manufacture of mucoadhesive forms in the case of poorly soluble drugs $25-28$.

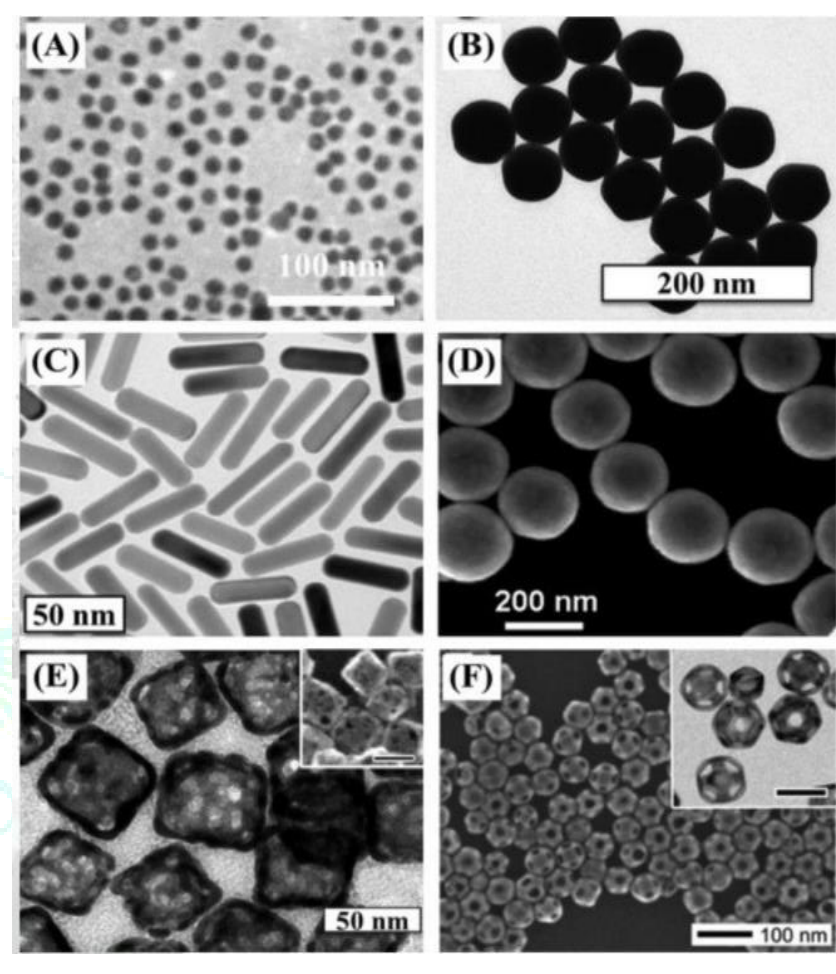

Figure1: SEM images of different AuNP sizes and shapes used in biomedical. (A) $15 \mathrm{~nm}$ nanospheres using (B) $150 \mathrm{~nm}$ spheres (C) nanorods, (D) nanoshells, (E) cubic nanocages (F) nanocages.

\section{Advantages \& Usage of Au Gold Nanoparticles:}

Although the mechanism(s) involved is not fully known, nanoparticles can quickly penetrate cells via endocytosis, the nanoparticle influx occurs; the particles are incorporated and diffused across the cell membrane lipid bilayer. Also, even after binding to proteins such as antibodies, these nanoparticles were found to be able to penetrate the cells. For precise binding to cancer cells, nanoparticles conjugated with antibodies toward exclusive cancer cell surface receptors were used; functionalized nanoparticles were also used for direct entry into cells. Phthalocyanine-stabilized gold nanoparticles are a possible photodynamic therapy delivery tool 29-31. To provide functional nanoparticles that invade the biological membrane and enter the nucleus, gold 
nanoparticles with a size of $20 \mathrm{~nm}$ are being conjugated to diverse cell-binding peptides. And for detection and medical treatment of cancer, numerous nanoparticles are most often used as selective biomarkers and drug delivery agents. In the synthesis of gold nanoparticles, chitosan may be an advantage for biological applications, used as a reducing agent, act as a drug carrier for the development of DNA 32-35. Studies say that nanofibrous chitosan membrane regulate the release of the simvastatin-hydrophobic drug, and nanofibers made from natural or synthetic polymers developed by electrospinning have been effective for wound treatment 36-39. Another study shows the use of electrospinning methods and materials used for nanofibrous scaffolds, applications in gene therapy 40-43. Low molecular weight chitosan-based atorvastatin nanocrystals formulation can be a promising alternative to enhance the oral bioavailability of the large class of biopharmaceutical drugs. Chitosan-based micro-particles packed with Ellagic acid have improved cytotoxic and proapoptotic activity against colon cancer. Another research showed that simvastatin chitosan microparticles loaded with have improved proapoptotic activity and cytotoxicity against colon cancer cells 44-47. Nanoparticles packed with chitosan-coated in situ gel simvastatin are effective in the treatment of human squamous cell carcinoma in the tongue. Nanocrystal-based chitosan atorvastatin packed with poly (lactic-co-glycolic) acid (PLGA) has showed increased hypolipidemic effect and

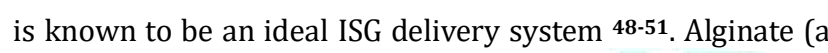
natural polysaccharide) is the most commonly known biomaterial used in drug delivery and targeting, representing a modern approach to the synthesis of nanoparticles and microparticles. The study showed the use of an alginatebased drug delivery device in dentistry to treat multiple dental diseases. The study demonstrates recent advancements in drug distribution and drug targeting of alginate nanoparticles and its limitation as nano-carriers in drug delivery and uses in pharmaceutical nanomaterials. The study indicates that alginate-based hydrogel wound dressings are effective in wound healing therapy 52-56.

\section{Polymers used in the delivery of Au Gold nanoparticles:}

Research analysis has shown that polyvinylpyrrolidone (PVP) as a polymer has proved to be protective and prophylaxis assistance to COVID-19 during the pandemic situation. The research shows the possible use of PVP (Polyvinylpyrrolidone) based nano scaffolds in various ISSN: 2250-1177 biomedical implants, ophthalmic, and wound healing material, and more with a novel approach of PVP biomedical materials for 3D and 4D printing. Any of the uses of these $\mathrm{Au}$ nanoparticles include precise targeting and drug delivery, but the protective properties of endothelial extracellular matrices hamper particle uptake. We define a method of synthesis for ultra-small gold nanoparticles to enhance vascular distribution to solve this issue, with adjustable functional groups and polymer lengths for further changes $2.5 \mathrm{~nm} \mathrm{Au}$ nanoparticles that are coated by tetrakis (hydroxymethyl)phosphonium chloride (THPC) are provided by the procedure. The substitution of THPC on the surface of the AuNP by hetero-functional polyethylene glycol (PEG) improves the hydrodynamic radius to $10.5 \mathrm{~nm}$ thereby having separate surface functional groups 57-62. Also, the spectrum of the size of these nanoparticles makes these just an excellent choice for glycocalyx testing while affecting natural vasculature operation, which can lead to enhanced delivery and therapeutics. Electrospinning technology has advanced in such a way that modified ultrafine nanofibers with controlled morphology and desired purpose can be used for synthetic or natural polymers.

\section{Lipids used in the delivering of gold nanoparticles:}

Studies have shown that solid lipid nanoparticles with transdermal film loaded avanafil have been effective in oral management. Pro-liposomes are promising drug carriers for various drug delivery, providing major advances in finding a solution to the stability, bioavailability, solubility of poorly soluble drugs associated with liposomes. Research showed that prednisolone proliposomal gel has a potential for transdermal delivery could be useful in the treatment of rheumatoid arthritis. Also, the study demonstrated a novel method using RP-HPLC that could be useful in evaluating the quantitative and entrapment efficacy of prednisolone in the estimation of proliposome gel formulation. A study described the preparation of piroxicam proliposomal gel showed improved anti-inflammatory activity and efficacy in the treatment of rheumatoid arthritis. The study highlights the optimization of glimepiride (GMD) transdermal liposomal films using quality-based design (QbD) and process analytical technology (PAT) principles as a near-infrared analysis [30]. Self-nano-emulsifying drug delivery system (SNEDDS) is one of the lipid-based nano-carrier formulations that demonstrate a promising approach to overcoming oral bioavailability and low drug solubility. A research study [153 
indicates that SNEDDS could be useful as a possible drug carrier to facilitate the dissolution of atorvastatin 63-69. Miconazole nitrate self-nanoemulsion with hyaluronic acidbased oral gel showed improved antifungal activity and oral thrush therapy. Notable in vitro experiments have shown that the inclusion of $G$ nanoparticles in existing radiation therapy procedures gets better results for significant clinical intensity-modulated energies. Using its leaky blood vessels, intravenous administration Nanoparticles can collect inside the tumor, penetrate through tumor tissue, and ultimately enter the individual cancer cells $\mathbf{7 0}$. However, based on the specific tumor microenvironment, the GNP aggregation and radioactive accuracy of estimation may be different. Implementation of Gold nanoparticles into an NP scheme based on lipids' future initiatives in chemotherapy will encourage this. Natural lipids, generally phospholipids and cholesterol, are composed of lipid nanoparticles which can encapsulate particles in a hydrophilic or hydrophobic core. We used an LNP system that delivers smaller Golf nanoparticles (LNP-GNP) throughout this analysis as a Trojan horse 71. Metallic nanoparticles' lipid encapsulation is a great way to improve their internalization and biocompatibility, as lipid surface chemistry is comparable to cell membrane structural components. As a carrier for genes and drug delivery, lipid nanoparticles are also of interest. Finally, for potential combination therapeutics, lipid nanoparticles offer fresh ways to encapsulate all Gold nanoparticles and anticancer medicines in one vehicle 72-74.

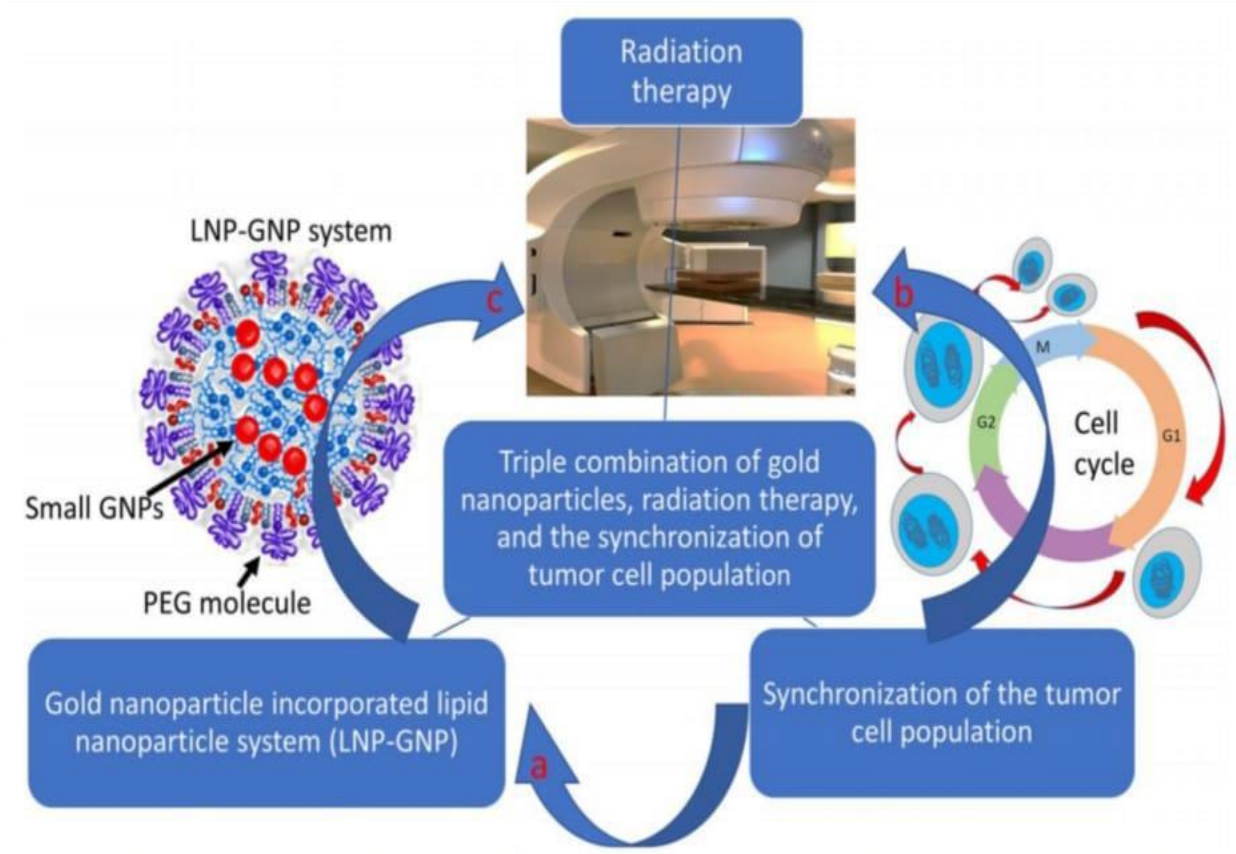

Figure 2: Schematic representation of modern lipid-based NP platform in human breast cancer cells, the mixture of Gold nanoparticles and alignment of the cancer cells demographic influences the outcome in radiation therapy.

One of the pathways for growing the death of cells is seen in Figure 2, where the most free radicals may be generated by the existence of Gold nanoparticles, contributing to even more DNA damage. For cells treated with lipid based Gold nanoparticles, the surviving percentage was lower. To evaluate the radiation-induced damage. However, following treatment with radiation, there was no substantial change in DNA damage in cells treated with LNP-Gold nanoparticles. This is aligned with the clonogenic assay findings. The configuration of the particle acceleration was used for the radiation experiment. The tumor cell populations to further improve the nanoparticle uptake and maximize the therapeutic outcome $\mathbf{7 5}$.

\section{Conclusion:}

These novel nanocrystals polymer particles are effective in delivering to nanoscale regions within the body that are difficult to penetrate with minimal disruption of the body about the surrounding environment. The inclusion of the PEG makes it possible to improve biocompatibility and provides functional groups for heavy particle customization for various purposes. The smaller size comes with limitations 
compared to traditional nanoparticles, but if developed. Appropriately, in vascular targeting and drug delivery, the ultrasmall particle is a viable candidate for handling the hard-to-penetrate, intricate, and delicate glycocalyx. A threefold combination of synchronization of the cell cycle, delivery of Gold nanoparticles, and radiation treatment has the potential to significantly enhance breast cancer treatment outcome. Excellent potential in cell killing was provided by improved uptake and radiation sensitivity of the coordinated MDA-MB-231 triple-negative breast cell population. Synchronizing cells and attaching Lipid nanoparticles into tumor cells, for example, produced a $27 \%$ growth compared to control (unsynchronized; no Gold nanoparticles; 2 Gy) in tumor cell death. Even a smaller increase in cell death with a single dose fraction will, as predicted in this report, lead to a substantial increase when multiple dosages are used throughout therapy. Therefore, the design and creation of GNP delivery systems based on polymer \& lipid-NP were driven by the aim of developing new materials and devices in future cancer nanomedicine with superior properties, functions, efficiencies, and protection. We assume that shortly, a mixture of cell cycle synchronization, Gold nanoparticles, radiation therapy, and anticancer medications will have additional synergistic benefits in improving the treatment of GNP-mediated cancer.

\section{References}

1. Cai W, Gao T, Hong H, Sun J. Applications of gold nanoparticles in cancer nanotechnology. Nanotechnology, science and applications. 2008; 1:17.

2. Abdelhady, S., Honsy, K. M., \& Kurakula, M. Electro SpunNanofibrous Mats: A Modern Wound Dressing Matrix with a Potential of Drug Delivery and Therapeutics. Journal of Engineered Fibers and Fabrics, 2015; 10(4):155892501501000. https://doi.org/10.1177/155892501501000411

3. El-Sayed IH, Huang X, El-Sayed MA. Surface plasmon resonance scattering and absorption of anti-EGFR antibody conjugated gold nanoparticles in cancer diagnostics: applications in oral cancer. Nano letters. 2005 May 11; 5(5):829-34.

4. Ahmed, O. A. A., Kurakula, M., Banjar, Z. M., Afouna, M. I., \& Zidan, A. S. Quality by design coupled with near infrared in formulation of transdermal glimepiride liposomal films. Journal of Pharmaceutical Sciences, 2015; 104(6):2062-2075. https://doi.org/10.1002/jps.24448

5. Alhakamy, N. A., Ahmed, O. A. A., Kurakula, M., Caruso, G., Caraci, F., Asfour, H. Z., Alfarsi, A., Eid, B. G., Mohamed, A. I., Alruwaili, N. K., Abdulaal, W. H., Fahmy, U. A., Alhadrami, H. A., Eldakhakhny, B. M., \& Abdel-Naim, A. B. Chitosan-based microparticles enhance ellagic acid's colon targeting and proapoptotic activity.
Pharmaceutics, 2020; 12(7):1-14.

https://doi.org/10.3390/pharmaceutics12070652

6. Kang B, Mackey MA, El-Sayed MA. Nuclear targeting of gold nanoparticles in cancer cells induces DNA damage, causing cytokinesis arrest and apoptosis. Journal of the American Chemical Society. 2010 Feb 10; 132(5):1517-9.

7. Lim ZZ, Li JE, Ng CT, Yung LY, Bay BH. Gold nanoparticles in cancer therapy. Acta Pharmacologica Sinica. 2011 Aug; 32(8):983-90.

8. Alhakamy, N. A., Fahmy, U. A., Ahmed, O. A. A., Caruso, G., Caraci, F., Asfour, H. Z., Bakhrebah, M. A., Alomary, M. N., Abdulaal, W. H., Okbazghi, S. Z., Abdel-Naim, A. B., Eid, B. G., Aldawsari, H. M., Kurakula, M., \& Mohamed, A. I. Chitosan coated microparticles enhance simvastatin colon targeting and pro-apoptotic activity. Marine Drugs, 2020; 18(4):226. https://doi.org/10.3390/md18040226

9. Haume K, Rosa S, Grellet S, Śmiałek MA, Butterworth KT, Solov'yov AV, Prise KM, Golding J, Mason NJ. Gold nanoparticles for cancer radiotherapy: a review. Cancer nanotechnology. 2016 Dec $1 ; 7(1): 8$.

10. Hasnain, M. S., Kiran, V., Kurakula, M., Rao, G. K., Tabish, M., \& Nayak, A. K. Use of alginates for drug delivery in dentistry. In Alginates in Drug Delivery 2020; 387-404. Elsevier. https://doi.org/10.1016/b978-0-12-817640-5.00015-7

11. Huang X, El-Sayed MA. Gold nanoparticles: Optical properties and implementations in cancer diagnosis and photothermal therapy. Journal of advanced research. 2010 Jan 1; 1(1):13-28.

12. Hasnain, M. S., Nayak, A. K., Kurakula, M., \& Hoda, M. N. Alginate nanoparticles in drug delivery. In Alginates in Drug Delivery 2020; 129-152. Elsevier. https://doi.org/10.1016/b978-0-12817640-5.00006-6

13. Mansoori GA, Brandenburg KS, Shakeri-Zadeh A. A comparative study of two folate-conjugated gold nanoparticles for cancer nanotechnology applications. Cancers. 2010 Dec; 2(4):1911-28.

14. Hosny, K. M., Aldawsari, H. M., Bahmdan, R. H., Sindi, A. M., Kurakula, M., Alrobaian, M. M., Aldryhim, A. Y., Alkhalidi, H. M., Bahmdan, H. H., Khallaf, R. A., \& El Sisi, A. M. Preparation, Optimization, and Evaluation of Hyaluronic Acid-Based Hydrogel Loaded with Miconazole Self-Nanoemulsion for the Treatment of Oral Thrush. AAPS PharmSciTech, 2019; 20(7):297. https://doi.org/10.1208/s12249-019-1496-7

15. Chen W, Zhang S, Yu Y, Zhang H, He Q. Structural-engineering rationales of gold nanoparticles for cancer theranostics. Advanced Materials. 2016 Oct; 28(39):8567-85.

16. Kurakula, M., \& A. Ahmed, T. Co-Delivery of Atorvastatin Nanocrystals in PLGA based in situ Gel for Anti-Hyperlipidemic Efficacy. Current Drug Delivery, 2015; 13(2):211-220. https://doi.org/10.2174/1567201813666151109102718

17. Chen WH, Xu XD, Jia HZ, Lei Q, Luo GF, Cheng SX, Zhuo RX, Zhang XZ. Therapeutic nanomedicine based on dual-intelligent functionalized gold nanoparticles for cancer imaging and therapy in vivo. Biomaterials. 2013 Nov 1; 34(34):8798-807. 
18. Kurakula, M., Ahmed, O. A. A., Fahmy, U. A., \& Ahmed, T. A. Solid lipid nanoparticles for transdermal delivery of avanafil: optimization, formulation, in-vitro and ex-vivo studies. Journal of Liposome Research, 2016; 26(4):288-296. https://doi.org/10.3109/08982104.2015.1117490

19. Shah NB, Dong J, Bischof JC. Cellular uptake and nanoscale localization of gold nanoparticles in cancer using label-free confocal Raman microscopy. Molecular pharmaceutics. $2011 \mathrm{Feb}$ 7; 8(1):176-84.

20. Kurakula, M., El-Helw, A. M., Sobahi, T. R., \& Abdelaal, M. Y. Chitosan based atorvastatin nanocrystals: Effect of cationic charge on particle size, formulation stability, and in-vivo efficacy. International Journal of Nanomedicine, 2015; 10:321334. https://doi.org/10.2147/IJN.S77731

21. Li J, Gupta S, Li C. Research perspectives: gold nanoparticles in cancer theranostics. Quantitative imaging in medicine and surgery. 2013 Dec; 3(6):284.

22. Reddy, Kallem Sharat Venkat. Pembrolizumab in the Treatment of Metastatic Non-Small Cell Lung Cancer. 2020, 10.18535/jmscr/v8i9.35.

23. Kurakula, M., \& Koteswara Rao, G. S. N. Moving polyvinyl pyrrolidone electrospun nanofibers and bioprinted scaffolds toward multidisciplinary biomedical applications. European Polymer Journal, 2020; 136:109919. https://doi.org/10.1016/j.eurpolymj.2020.109919

24. Abadeer NS, Murphy CJ. Recent progress in cancer thermal therapy using gold nanoparticles. The Journal of Physical Chemistry C. 2016 Mar 10; 120(9):4691-716.

25. Huang X, Jain PK, El-Sayed IH, El-Sayed MA. Gold nanoparticles: interesting optical properties and recent applications in cancer diagnostics and therapy.

26. Kurakula, M., Naveen, N. R., \& Yadav, K. S. Formulations for Polymer Coatings. Polymer Coatings, 2020; 415-443. https://doi.org/10.1002/9781119655145.ch19

27. Abadeer NS, Murphy CJ. Recent progress in cancer thermal therapy using gold nanoparticles. The Journal of Physical Chemistry C. 2016 Mar 10; 120(9):4691-716.

28. Kurakula, M., \& Raghavendra Naveen, N. In situ gel loaded with chitosan-coated simvastatin nanoparticles: Promising delivery for effective anti-proliferative activity against tongue carcinoma. Marine Drugs, 2020; 18(4):201. https://doi.org/10.3390/md18040201

29. Peng J, Liang X. Progress in research on gold nanoparticles in cancer management. Medicine. 2019 May; 98(18).

30. Naguib, G. H., Hassan, A. H., Al-Hazmi, F., Kurakula, M., AlDharrabh, A., Alkhalidi, H. M., Al-Ahdal, A. M., Hamed, M. T., \& Pashley, D. H. Zein based magnesium oxide nanowires: Effect of anionic charge on size, release and stability. Digest Journal of Nanomaterials and Biostructures, 2017; 12(3):741-749.

31. Kurakula, M., Rao, G. K., Kiran, V., Hasnain, M. S., \& Nayak, A. K. Alginate-based hydrogel systems for drug releasing in wound healing. In Alginates in Drug Delivery, 2020; 323-358. Elsevier. https://doi.org/10.1016/b978-0-12-817640-5.00013-3

32. Shi X, Wang SH, Lee I, Shen M, Baker Jr JR. Comparison of the internalization of targeted dendrimers and dendrimerentrapped gold nanoparticles into cancer cells. Biopolymers: Original Research on Biomolecules. 2009 Nov; 91(11):936-42.

33. Rao, G. S. N. K., Kurakula, M., \& Yadav, K. S. Application of Electrospun Materials in Gene Delivery. Electrospun Materials and Their Allied Applications, 2020; 265-306

34. Reddy, K. S. V. Understanding Novel Polymer and Lipid Based Carrier Systems In Clinician Perspective. International Journal of Medical Science And Diagnosis Research, 2020; 4(10).

35. Shi X, Wang SH, Lee I, Shen M, Baker Jr JR. Comparison of the internalization of targeted dendrimers and dendrimerentrapped gold nanoparticles into cancer cells. Biopolymers: Original Research on Biomolecules. 2009 Nov; 91(11):936-42.

36. Kurakula, M., \& Rao, G. S. N. K. Pharmaceutical assessment of polyvinylpyrrolidone (PVP): As excipient from conventional to controlled delivery systems with a spotlight on COVID-19 inhibition. Journal of Drug Delivery Science and Technology, 2020; 60:102046. https://doi.org/10.1016/j.jddst.2020.102046

37. Popovtzer R, Agrawal A, Kotov NA, Popovtzer A, Balter J, Carey TE, Kopelman R. Targeted gold nanoparticles enable molecular CT imaging of cancer. Nano letters. 2008 Dec 10; 8(12):4593-6.

38. Kurakula, M., Sobahi, T. R., El-Helw, A., \& Abdelaal, M. Y. Development and validation of a RP-HPLC method for assay of atorvastatin and its application in dissolution studies on thermosensitive hydrogel-based nanocrystals. Tropical Journal of Pharmaceutical Research, 2014; 13(10):1681-1687. https://doi.org/10.4314/tjpr.v13i10.16

39. Dreaden EC, Austin LA, Mackey MA, El-Sayed MA. Size matters: gold nanoparticles in targeted cancer drug delivery. Therapeutic delivery. 2012 Apr; 3(4):457-78.

40. Oh MH, Yu JH, Kim I, Nam YS. Genetically programmed clusters of gold nanoparticles for cancer cell-targeted photothermal therapy. ACS applied materials \& interfaces. 2015 Oct 14; $7(40): 22578-86$.

41. Kurakula, M., Srinivas, C., Kasturi, N., \& Diwan, P. V. Formulation and Evaluation of Prednisolone Proliposomal Gel for Effective Topical Pharmacotherapy. International Journal of Pharmaceutical Sciences and Drug Research, 2012; 4(1):35. www.ijpsdr.com

42. Vines JB, Yoon JH, Ryu NE, Lim DJ, Park H. Gold nanoparticles for photothermal cancer therapy. Frontiers in chemistry. 2019 Apr 5; 7:167.

43. Peng G, Tisch U, Adams O, Hakim M, Shehada N, Broza YY, Billan S, Abdah-Bortnyak R, Kuten A, Haick H. Diagnosing lung cancer in exhaled breath using gold nanoparticles. Nature nanotechnology. 2009 0ct; 4(10):669-73.

44. Mallesh, K., Pasula, N., \& Kumar Ranjith, C. P. Piroxicam proliposomal gel: a novel approach for tropical delivery. Journal of Pharmacy Research, 2012; 5(3):1755-1763. 
45. Kurakula M, Mohd AB, Samhuidrom AP, Diwan PV. Estimation of prednisolone in proliposomal formulation using RP HPLC method. Int. J. Res. Pharm. Biomed. Sci. 2011; 2:663. 2011;1669.

46. Kurakula M, Naveen NR. Prospection of recent chitosan biomedical trends: Evidence from patent analysis (2009-2020). International Journal of Biological Macromolecules. 2020 Oct 15.

47. Nam J, Won N, Jin H, Chung H, Kim S. pH-induced aggregation of gold nanoparticles for photothermal cancer therapy. Journal of the American Chemical Society. 2009 Sep 30; 131(38):13639-45.

48. Venkatesh, M., \& Mallesh, K. Self-Nano Emulsifying Drug Delivery System (Snedds) for Oral Delivery of AtorvastatinFormulation and Bioavailability Studies. Journal of Drug Delivery and Therapeutics, 2013; 3(3):131-140. https://doi.org/10.22270/jddt.v3i3.517

49. Reddy, K. S. V. Clinical implications of novel polymer and lipid based drug delivery systems. International Journal of Research in Hospital and Clinical Pharmacy, 2020; 2(3):60-65.

50. Kurakula M, Mohd AB, Samhuidrom AP, Diwan PV. Estimation of prednisolone in proliposomal formulation using RP HPLC method. Int. J. Res. Pharm. Biomed. Sci. 2011; 2: 663. 2011; 1669.

51. Patskovsky S, Bergeron E, Rioux D, Meunier M. Wide-field hyperspectral 3D imaging of functionalized gold nanoparticles targeting cancer cells by reflected light microscopy. Journal of biophotonics. 2015 May; 8(5):401-7.

52. Liang H, Tian H, Deng M, Chen X. Gold nanoparticles for cancer theranostics. Chinese Journal of Chemistry. 2015 Sep; 33(9):1001-10.

53. Murali, V. P., Fujiwara, T., Gallop, C., Wang, Y., Wilson, J. A., Atwill, M. T., Kurakula, M., \& Bumgardner, J. D. Modified electrospun chitosan membranes for controlled release of simvastatin. International Journal of Pharmaceutics, 2020; 584:119438. https://doi.org/10.1016/j.ijpharm.2020.119438

54. Tian L, Lu L, Qiao Y, Ravi S, Salatan F, Melancon MP. Stimuliresponsive gold nanoparticles for cancer diagnosis and therapy. Journal of functional biomaterials. 2016 Sep; 7(3):19.

55. Fralick, M., Macdonald, E. M., Gomes, T., Antoniou, T., Hollands, S., Mamdani, M. M., \& Juurlink, D. N. Co-trimoxazole and sudden death in patients receiving inhibitors of renin-angiotensin system: population based study. Bmj, 2014; 349, g6196.

56. Wang F, Wang YC, Dou S, Xiong MH, Sun TM, Wang J. Doxorubicin-tethered responsive gold nanoparticles facilitate intracellular drug delivery for overcoming multidrug resistance in cancer cells. ACS nano. 2011 May 24; 5(5):3679-92.

57. Raoof M, Corr SJ, Kaluarachchi WD, Massey KL, Briggs K, Zhu C, Cheney MA, Wilson LJ, Curley SA. Stability of antibodyconjugated gold nanoparticles in the endolysosomal nanoenvironment: implications for noninvasive radiofrequencybased cancer therapy. Nanomedicine: Nanotechnology, Biology and Medicine. 2012 Oct 1; 8(7):1096-105.

58. Naguib, Ghada Hussein, Al-Hazmi, F. E., Kurakula, M., Abdulaziz Al-Dharrab, A., Mohamed Hosny, K., Mohammed Alkhalidi, H.,
Tharwat Hamed, M., Habiballah Hassan, A., Al-Mohammadi, A. M., Mohamed Alnowaiser, A., \& Henry Pashley, D. Zein coated zinc oxide nanoparticles: Fabrication and antimicrobial evaluation as dental aid. International Journal of Pharmacology, 2018; 14(8):1051-1059. https://doi.org/10.3923/ijp.2018.1051.1059

59. Her S, Jaffray DA, Allen C. Gold nanoparticles for applications in cancer radiotherapy: Mechanisms and recent advancements. Advanced drug delivery reviews. 2017 Jan 15; 109:84-101.

60. Arias, J. L. (Ed.). (2014). Nanotechnology and drug delivery, volume one: nanoplatforms in drug delivery (Vol. 1). CRC Press.

61. Steinman, M. A., \& Hanlon, J. T. Managing medications in clinically complex elders: "There's got to be a happy medium". Jama, 2010; 304(14):1592-1601.

62. Naveen, N. R., Gopinath, C., \& Kurakula, M. Okra-thioglycolic acid conjugate-synthesis, characterization, and evaluation as a mucoadhesive polymer. Processes, 2020; 8(3):316. https://doi.org/10.3390/pr8030316

63. Kong T, Zeng J, Wang X, Yang X, Yang J, McQuarrie S, McEwan A, Roa W, Chen J, Xing JZ. Enhancement of radiation cytotoxicity in breast-cancer cells by localized attachment of gold nanoparticles. small. 2008 Sep; 4(9):1537-43.

64. Huang CW, Hao YW, Nyagilo J, Dave DP, Xu LF, Sun XK. Porous hollow gold nanoparticles for cancer SERS imaging. InJournal of Nano Research. Trans Tech Publications Ltd. 2010; 10:137-148.

65. Raghavendra Naveen, N., Kurakula, M., \& Gowthami, B. Process optimization by response surface methodology for preparation and evaluation of methotrexate loaded chitosan nanoparticles. Materials Today: 2020. https://doi.org/10.1016/j.matpr.2020.01.491

66. Mesbahi A. A review on gold nanoparticles radiosensitization effect in radiation therapy of cancer. Reports of Practical Oncology \& Radiotherapy. 2010 Nov 1; 15(6):176-80.

67. Le Goas M, Paquirissamy A, Gargouri D, Fadda G, Testard F, Aymes-Chodur C, Jubeli E, Pourcher T, Cambien B, Palacin S, Renault JP. Irradiation effects on polymer-grafted gold nanoparticles for cancer therapy. ACS Applied Bio Materials. 2018 Dec 7; 2(1):144-54.

68. Vanitasagar, S., Srinivas, C., Subhashini, N. J. P., \& Mallesh, K. Solid dispersion-a comparative study on the dissolution rate of aceclofenac. International Journal of Pharmacy and Pharmaceutical Sciences, 2012; 4(SUPPL.3), 274-278.

69. Choi CH, Alabi CA, Webster P, Davis ME. Mechanism of active targeting in solid tumors with transferrin-containing gold nanoparticles. Proceedings of the National Academy of Sciences. 2010 Jan 19; 107(3):1235-40.

70. Kodiha M, Wang YM, Hutter E, Maysinger D, Stochaj U. Off to the organelles-killing cancer cells with targeted gold nanoparticles. Theranostics. 2015; 5(4):357.

71. Zhang Z, Jia J, Lai Y, Ma Y, Weng J, Sun L. Conjugating folic acid to gold nanoparticles through glutathione for targeting and 
detecting cancer cells. Bioorganic \& medicinal chemistry. 2010 Aug 1; 18(15):5528-34.

72. Chauhan A, Zubair S, Tufail S, Sherwani A, Sajid M, Raman SC, Azam A, Owais M. Fungus-mediated biological synthesis of gold nanoparticles: potential in detection of liver cancer. International journal of nanomedicine. 2011; 6:2305.

73. Bhattacharya R, Patra CR, Earl A, Wang S, Katarya A, Lu L, Kizhakkedathu JN, Yaszemski MJ, Greipp PR, Mukhopadhyay D, Mukherjee P. Attaching folic acid on gold nanoparticles using noncovalent interaction via different polyethylene glycol backbones and targeting of cancer cells. Nanomedicine:
Nanotechnology, Biology and Medicine. 2007 Sep 1; 3(3):22438.

74. Rengan AK, Bukhari AB, Pradhan A, Malhotra R, Banerjee R, Srivastava R, De A. In vivo analysis of biodegradable liposome gold nanoparticles as efficient agents for photothermal therapy of cancer. Nano letters. 2015 Feb 11; 15(2):842-8.

75. Huang YF, Lin YW, Lin ZH, Chang HT. Aptamer-modified gold nanoparticles for targeting breast cancer cells through light scattering. Journal of Nanoparticle Research. 2009 May 1; 11(4):775-83. 